\title{
Las organizaciones de economía solidaria como mecanismo de integración de pequeños y medianos productores de yuca en Yopal, Casanare (Colombia)
}

\author{
Sandra Milena Cárdenas-Mora*, Kelly Johanna Manzanares-Mendoza**, Alicia Milena
}

Torres-Cárdenas ${ }^{* * *}$

Magíster en Administración. Universidad de La Salle, Bogotá, Colombia. Correo electrónico: scardenasas@unisalle.edu.co

** Contadora pública. Universidad de La Salle, Bogotá, Colombia. Correo electrónico: kmanzanares26@unisalle.edu.co

*** Magíster en Planeación del Desarrollo Socioeconómico. Docente investigadora asistente III, Facultad de Ciencias Administrativas y Contables, Universidad de La Salle, Bogotá, Colombia. Correo electrónico: atorres@unisalle.edu.co

Recibido: 22 de agosto del 2016

Aprobado: 7 de noviembre del 2016

Cómo citar este artículo: CárdenasMora, S. M., Manzanares-Mendoza, K. J. y Torres-Cárdenas, A. M. (2017). Las organizaciones de economía solidaria como mecanismo de integración de pequeños y medianos productores de yuca en Yopal, Casanare (Colombia). Cooperativismo \& Desarrollo, 110(25), 27-36. doi: https://doi. org/10.16925/co.v25i110.1762.

\section{Resumen}

Propósito: este trabajo tiene como propósito plantear alternativas económicas y sociales para la organización de pequeños y medianos productores de yuca en Yopal, Casanare, a partir de la conformación de organizaciones que se fundamenten en los principios de economía solidaria. Descripción: en su desarrollo, se reconoce la importancia económica de la yuca en la región y se expone la cadena de valor de la yuca. Punto de vista: como forma de organización, se analizan las formas asociativas solidarias, así como las posibilidades que dichas organizaciones ofrecen como mecanismos empresariales que dinamicen la producción y comercialización de la yuca en Yopal, Casanare. Conclusiones: en el contexto de los productores de yuca de Yopal, las organizaciones solidarias se constituyen en un mecanismo viable para unificar esfuerzos y obtener importantes beneficios colectivos, razón por la cual dichas organizaciones se configuran como eje de esta reflexión, al tener en cuenta además el potencial económico de la yuca en esta población.

Palabras clave: cadena de valor, economía solidaria, Yopal, yuca. 


\title{
Solidarity Economy Organizations as a Mechanism for the Integration of Small And Medium Cassava Producers in Yopal, Casanare (Colombia)
}

\begin{abstract}
Purpose: The purpose of this paper is to propose economic and social alternatives for the management of small and medium cassava producers in Yopal, Casanare (Colombia), based on the constitution of organizations grounded on the principles of solidarity economy. Description: Throughout the paper, the economic importance of cassava in the region is acknowledged, and the value chain of cassava is exposed. Point of view: The associative solidary systems are analyzed as a form of organization, as well as the possibilities offered by these as business mechanisms to stimulate the production and commercialization of cassava in Yopal, Casanare. Conclusions: Solidarity organizations constitute a viable mechanism to unite efforts and obtain important collective benefits in the context of Yopal's cassava producers, which is why these organizations form the basis of the present reflection, taking into account the economic potential of cassava in this population.
\end{abstract}

Keywords: value chain, solidarity economy, Yopal, cassava.

\section{As organizações de economia solidária como mecanismo de integração de pequenos e médios produtores de mandioca em Yopal, Casanare (Colômbia)}

\section{Resumo}

Propósito: este trabalho tem como propósito apresentar alternativas econômicas e sociais para a organização de pequenos e médios produtores de mandioca em Yopal, Casanare (Colômbia), a partir da conformação de organizações que se fundamentam nos princípios de economia solidária. Descrição: em seu desenvolvimento, reconhece-se a importância econômica da mandioca na região e expõe-se a cadeia de valor desse produto. Ponto de vista: como forma de organização, analisam-se as formas associativas solidárias bem como as possibilidades que essas organizações oferecem como mecanismos empresariais que dinamizam a produção e a comercialização da mandioca em Yopal. Conclusões: no contexto dos produtores de mandioca de Yopal, as organizações solidárias se constituem num mecanismo viável para unificar esforços e obter importantes benefícios coletivos, razão pela qual essas organizações se configuram como eixo desta reflexão, considerando, além disso, o potencial econômico da mandioca nessa população.

Palavras-chave: cadeia de valor, economia solidária, mandioca, Yopal. 


\section{Introducción}

Uno de los principales problemas a los que se ven abocados los campesinos en la región de Yopal es la dificultad que tienen para competir con las grandes compañías que se dedican a la producción y comercialización de bienes agrícolas.

En el fondo, esos problemas radican en gran medida en el desconocimiento que existe acerca de la cadena de valor de sus productos, y de los procesos administrativos y financieros básicos para generar crecimiento en sus negocios.

En ese orden de ideas, la existencia de formas asociativas de economía solidaria es una oportunidad para que estas personas tengan mecanismos alternativos de organización con el propósito de potenciar las capacidades y conocimientos que tienen de los negocios, específicamente en productos como la yuca.

Por lo mismo que se ha planteado, muchos campesinos prefieren emplearse a cambio de pagos que distan mucho de lo que realmente debería ser la remuneración por su trabajo. Desde el punto de vista del campesino que contrata, al no existir la costumbre de establecer contratos formales, presentan dificultades asociadas a no tener certeza sobre el personal con que cuentan y que repercute en mayor grado en los periodos de alta producción.

A raíz de lo anterior, el trabajo desarrollado busca identificar en las formas asociativas solidarias mecanismos de organización que le permitan a los pequeños productores de yuca de Yopal, Casanare, constituir equipos de trabajo que les faciliten el crecimiento y sostenimiento de sus negocios, al tiempo que van desarrollando estrategias que les permitan competir en mejores condiciones.

La investigación que da origen a este documento es de tipo descriptivo-evaluativo y utiliza métodos cuantitativos como estadísticas, tablas, entre otros, y cualitativos como observaciones, entrevistas, etc., con el propósito de identificar las etapas del proceso productivo del cultivo de la yuca realizadas por pequeños y medianos productores organizados en forma asociativa en Yopal.

Con el fin de cumplir con este propósito, el documento parte del reconocimiento de la importancia económica de la yuca en Colombia, para luego describir la cadena productiva, la cadena de valor, y el proceso requerido para su producción. Posteriormente se presentan las consideraciones básicas sobre una organización de economía solidaria como opción para estructurar el negocio, con el propósito de entender la manera como esta forma organizativa puede dinamizar los procesos de producción y comercialización de la yuca en pequeños y medianos productores en la región citada.

\section{Importancia económica de la yuca en Colombia}

La yuca es un cultivo propio de las regiones cálidas y templadas. Debido a la facilidad que tiene para adaptarse a suelos ácidos e infértiles, se considera un cultivo que soporta largos periodos sin lluvia, a la vez que es uno de los cultivos más eficientes en términos de calorías. Por otra parte, es un producto que a la vez genera subproductos, pues las raíces y el follaje pueden ser utilizados en otro tipo de industrias, y como alimento para animales. Así mismo, este cultivo, debido a que no requiere de mayores condiciones de almacenamiento (no es altamente perecedero) y a que es fácilmente transportable, se convierte en una alternativa viable económicamente. Pese a que existe gran variedad de cultivos de yuca, estudios revelan que variedades como la см 523-7, см 507-37 y SG 104-164 tienen unas tasas altas de productividad y rendimiento (Howeler y Ballesteros, 1987).

En Colombia las condiciones ideales de producción se ubican a una altura de 50 a $1800 \mathrm{msnm}$, con temperatura media de $20^{\circ} \mathrm{C}$ a $25^{\circ} \mathrm{C}$ y precipitaciones superiores a $2000 \mathrm{~mm}$ anuales, en suelos de textura franco arenosa, con buen drenaje ("Cultivo de grandes proyecciones”, 1998). Este cultivo es muy exigente a la luz, dado que es una planta típica de fotoperiodo corto, en promedio entre 10 a 12 horas de luz (Departamento de Ingeniería Agrónoma y Contenidos, 2012).

Dichas condiciones se encuentran presentes en Yopal, ya que se encuentra ubicado en una región tropical y que la hacen una región óptima para el desarrollo de este cultivo. Este municipio se ubica en el piedemonte de la cordillera Oriental; por su topografía, presenta tres pisos térmicos cuyas áreas son: cálido, $1906 \mathrm{~km}^{2}$; medio, $106 \mathrm{~km}^{2}$, y frío, $25 \mathrm{~km}^{2}$. El clima de esta ciudad es cálido tropical con una temperatura media anual de $26,5^{\circ} \mathrm{C}$ y una pluviosidad media anual de 325 milímetros (mm). La extensión total de Yopal es de $2771 \mathrm{~km}^{2}$, de los cuales $2760,53 \mathrm{~km}^{2}$ son extensión del área rural y $10,47 \mathrm{~km}^{2}$, del área urbana, lo que muestra que la actividad económica del municipio gira en torno a la extracción de petróleo, la agricultura y la ganadería. Por consiguiente, la ganadería vacuna es la principal actividad económica de 
la población, seguido de la agricultura, en la cual los principales cultivos son arroz riego, arroz secano mecanizado, palma africana, plátano, maíz tradicional, café y yuca (Alcaldía de Yopal, Casanare, s. f.).

En Colombia su cultivo se realiza a escala comercial en Antioquia, Atlántico, Bolívar, Cauca, Cesar, Córdoba, Magdalena, Norte de Santander, Santander y Sucre ("Cultivo de grandes proyecciones", 1998), y a una escala menor en los departamentos del Orinoco. Sin embargo, según Aguilera, "la región Orinoquía incrementó su área sembrada en los últimos años, pasando de 9467 hectáreas promedio anual, en el periodo de 1990 a 1999, a 13444 hectáreas promedio anual entre 2000 y 2009, ganando participación dentro del total nacional” (Aguilera-Díaz, 2012, p. 30), como se evidencia en la figura 1.

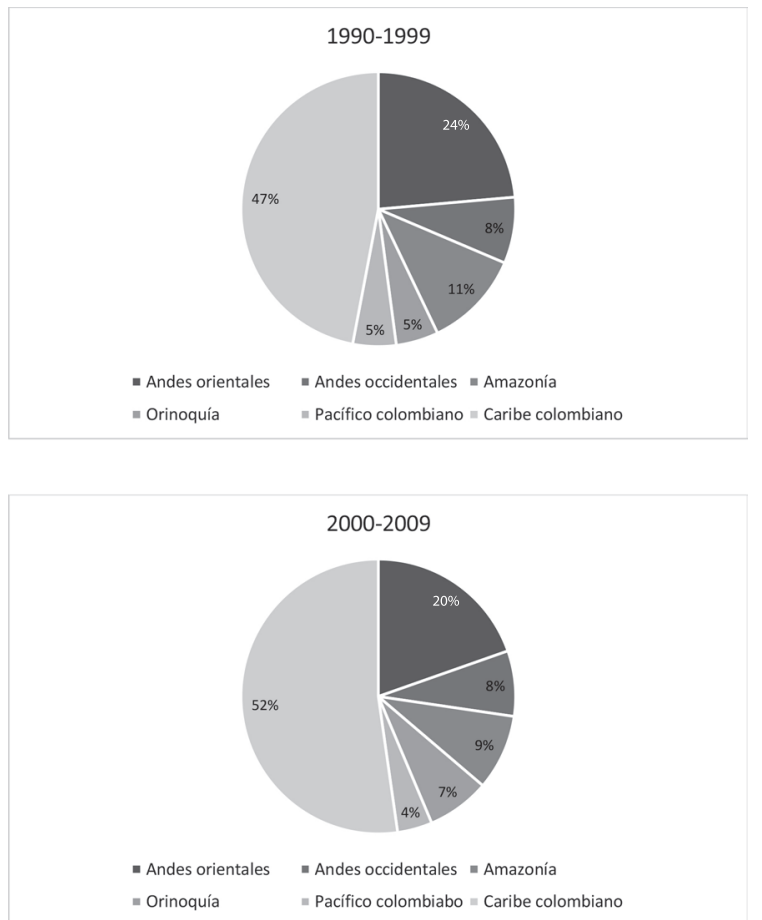

Figura 1. Distribución del área sembrada con yuca por regiones en los periodos 1990-1999 y 2000-2009. Tomado de La yuca en el caribe colombiano de cultivo ancestral a agroindustrial, Aguilera, 2012, Banco de la República, p. 30.

Actualmente, en Yopal, se siembran aproximadamente 450 hectáreas de yuca (Cáceres-Gómez, Pardo-Enciso y Torres-Cárdenas, 2012). El destino final de este producto es el consumo por las familias que lo producen, pero también se comercializa en los ámbitos local y regional.
De acuerdo con una investigación realizada sobre los antecedentes asociativos de la cadena productiva de yuca en Casanare, se conoce que aún no existe una definición de esta en la región, debido a que es un producto de siembra tradicional para un mercado regional y de consumo familiar, por lo que es un producto perecedero. Sin embargo, se encuentra entre las apuestas productivas con perspectivas de crecimiento en la región del Casanare (Botero-Soto, Delvasto-Rojas y Castro-González, 2013)

\section{Cadena productiva y cadena de valor de la yuca}

El cultivo de yuca pasa por diferentes etapas, como se muestra en la figura 2:

La cadena productiva de la yuca inicia con el proceso de diseño del cultivo, en el cual se establece la cantidad de hectáreas que el agricultor proyecta sembrar y el uso que este le dará (producción de alimento para el ser humano y animales, producción de almidones u otros productos, etc.). Luego está la etapa de producción, la cual se compone de cinco fases de producción: la extracción y recolección de estacas, la preparación del suelo, la siembra, el desarrollo del cultivo y la recolección del producto final.

Posterior a este proceso, se da la distribución y comercialización por hectáreas o toneladas al cliente final (familiares, vecinos o consumidores locales, empresas productoras de almidones, compradores y distribuidores nacionales, entre otros). En algunos casos, continúa con la etapa de transformación del producto final en un producto industrializado, tal como en el caso de los almidones de yuca.

Una de las herramientas que permite tener una comprensión ampliada del proceso en el manejo de la yuca es la cadena de valor, cuyos principios fueron planteados por Porter (2002), quien parte de reconocer las actividades que agregan valor en la búsqueda de lograr ventajas competitivas. En este proceso, se han de identificar dos tipos de actividades: primarias y secundarias; las primeras se refieren a la creación física del producto, su venta y servicios posventa, las cuales son apoyadas por las secundarias (infraestructura, dirección de recursos humanos, entre otros) (Arimany, 2010).

A partir del análisis realizado a la cadena productiva de la yuca se puede identificar la siguiente cadena de valor del negocio de la yuca en Colombia:

Actividades primarias:

- Logística interna: proyección de las hectáreas que se pretende sembrar; selección de tipo de yuca 


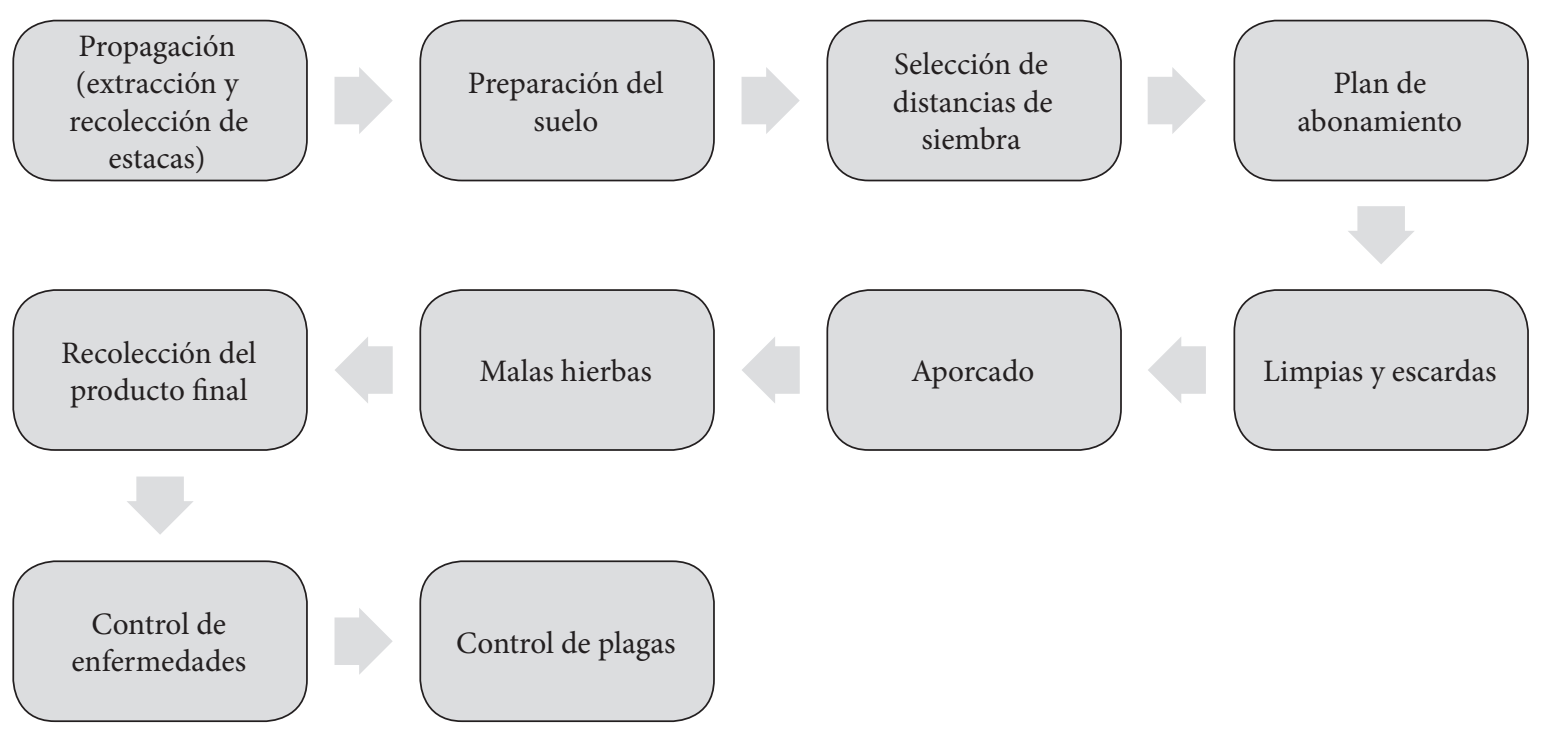

Figura 2. Proceso de producción de la yuca. Elaboración propia a partir de Aguilera-Díaz, 2012; Departamento de Ingeniería Agrónoma y Contenidos, 2012; CDPMм y Pronatta, 2001.

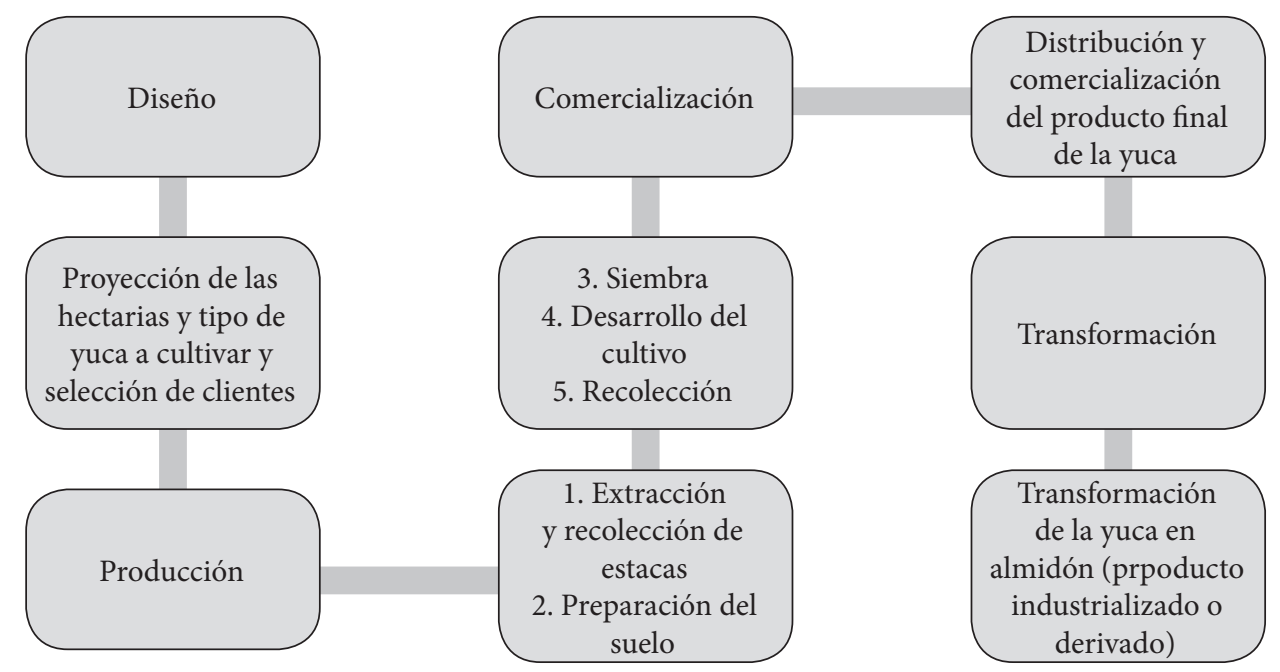

Figura 3. Cadena productiva de la yuca en Colombia. Elaboración propia.

que se va a cultivar y de clientes, y extracción y recolección de estacas.

- Operaciones (producción): preparación del suelo, siembra de estacas, desarrollo del cultivo de la yuca y recolección del producto final.

- Logística externa: almacenamiento de la yuca en una bodega y distribución en camionetas del producto final, la yuca, al consumidor.

- Marketing y ventas: venta de la yuca por toneladas, arrobas o libras en las plazas de mercado, tiendas, supermercados y otros; venta por toneladas a comerciantes de yuca al por mayor o empresas industriales que producen alimentos con base en la yuca (almidones, concentrados para animales, etc.).

- Servicio de posventa o mantenimiento: la producción de yuca no presta el servicio de posventa, debido a que se está tanto produciendo como vendiendo una materia prima y un producto perecedero. 
Actividades secundarias:

Si bien lo ideal sería contar con todas las áreas de apoyo señaladas, en el caso del objeto de estudio presentado, en la medida en que se trata de pequeños y medianos productores, lo recomendable sería que por lo menos se tuvieran como áreas de soporte un área contable o financiera; una administrativa, en la cual se llevara el control del recurso humano; una de almacén o bodega, encargada de hacer control tanto de las materias primas como del producto final (cosecha) y una dedicada a las herramientas y a la maquinaria que se utilizan en el proceso productivo.

\section{Desarrollo rural y organizaciones de economía solidaria}

El contexto político del país, las negociaciones de la Habana y la preocupación por atender las necesidades de los campesinos colombianos, conduce a repensar el campo colombiano desde nuevas estrategias de desarrollo, para este fin se elaboró el documento institucional "Misión para la trasformación del campo".

El cual parte de tres ideas fuerza, que pueden entenderse también como los principios básicos que deben regir las políticas de desarrollo rural: 1. La necesidad de fomentar un enfoque territorial participativo, que reconoce una ruralidad diferenciada y a los habitantes rurales como gestores y actores de su propio desarrollo. 2. La concepción del desarrollo como un proceso integral, que busca la inclusión, tanto social como productiva, de todos los habitantes rurales... considerar a los habitantes rurales tanto como agentes de desarrollo productivo como sujetos de derechos y, por ende, como plenos ciudadanos. 3. La necesidad de promover un desarrollo rural competitivo y ambientalmente sostenible basado, ante todo, en la provisión adecuada de bienes públicos que faciliten el desarrollo tanto de actividades agropecuarias como no agropecuarias (RIMISP, p. 6).

El reconocimiento al papel del campesino en el desarrollo significa que este sector de la población debe asumir un proceso de gobernanza participativa, es decir, ejercer una autoridad y una presencia en las políticas y acciones de transformación productiva, institucional y social de los territorios rurales junto con las instituciones del Estado y los demás actores públicos y privados. En este ejercicio democrático, la organización solidaria es una estrategia clave para que los habitantes rurales puedan asumir la responsabilidad de gestionar el desarrollo de sus territorios mediante la construcción de espacios institucionalizados en los que los entes territoriales del Estado y los actores sociales que hacen parte del territorio actúen de forma conjunta en la toma de decisiones.

El modelo de desarrollo rural basado en el enfoque territorial se fundamenta en la corriente sociologica llamada "la nueva ruralidad, la cual promueve la trasformación de aspectos fundamentales en el territorio rural: encadenamientos urbano-rurales, el empleo rural no agrícola, la provisión de servicios ambientales, las certificaciones agroambientales o "sellos verdes", los pueblos como centros de servicios, el papel activo de las comunidades y organizaciones sociales, y la diversidad ecológica-cultural como patrimonio" (Rojas-López, 2008).

Teniendo en cuenta los fundamentos del desarrollo territorial y el papel protagónico que desempeñan las comunidades y las organizaciones sociales en esta dinámica, la asociatividad toma gran importancia como mecanismo o medio que consolida alianzas entre personas, comunidades o empresas; facilita la cooperación entre entidades u organizaciones y favorece el acceso a la tecnología, la productividad, la eficiencia, la capacidad de negociación, los procesos de investigación y desarrollo para destrabar la parálisis de las pequeñas economías rurales arrinconadas y sometidas al callejón sin salida del minifundio y la descapitalización campesina:

Incorporarlas a la lógica territorial implica analizar las características actuales y potenciales de los territorios, la estructura productiva y los eslabonamientos posibles, con miras a generar mecanismos y procedimientos orientados a apoyar procesos de transformación. De esta forma, es un enfoque que pone atención sobre activos, actores y procesos intencionados de desarrollo (DNP, 2013).

Los sistemas de propiedad de la tierra, los usos del suelo y la mala distribución de los recursos en las zonas rurales colombianas son factores que contribuyen al empobrecimiento de la población campesina; las políticas públicas, lo mismo que las estrategias institucionales de desarrollo no han sido suficientes para abordar de forma adecuada la promoción del desarrollo rural.

Las organizaciones de economía solidaria desempeñan un papel importante para lograr la inclusión de los grupos de pequeños y medianos productores a 
los procesos de desarrollo de la economía rural y lograr que su actividad productiva sea reconocida con las ventajas de un trabajo decente. La Organización Internacional del Trabajo (огт) considera que las organizaciones de la economía solidaria son determinantes para mejorar tanto las condiciones de vida como las de trabajo de las mujeres y los hombres que trabajan en las actividades rurales, además de que contribuyen al mejoramiento de la calidad de vida proporcionando empleo y servicios fundamentales, como la atención de salud y la educación, y promueven que los principios y derechos fundamentales se cumplan.

En Colombia, el marco legal para la acción de las organizaciones de la economía solidaria lo proporcionan la Ley 79 de 1968 y la Ley 454 de 1998; la última, en el artículo 2, define la economía solidaria como:

El sistema socioeconómico, cultural y ambiental conformado por el conjunto de fuerzas sociales organizadas en formas asociativas identificadas por prácticas autogestionarias solidarias, democráticas y humanistas, sin ánimo de lucro para el desarrollo integral del ser humano como sujeto, actor y fin de la economía.

La creación de organizaciones de economía solidaria ha aumentado en los últimos años debido a los beneficios, los privilegios, las fuentes de financiación y las ventajas tributarias que ofrecen estas organizaciones. Es así como, para el 2012, y de acuerdo con lo señalado por Enrique Valencia Montoya, quien en ese año se desempeñaba como Superintendente de Economía Solidaria, en Colombia existían cerca de 6000 cooperativas, 2000 fondos de empleados y 263 asociaciones mutuales ("Economía solidaria, un sector en crecimiento", 2013). Así mismo, de acuerdo con información de la Superintendencia de Economía Solidaria, actualmente existen más de 20000 organizaciones de economía solidaria, de las cuales más de 4600 reportan actualmente información a dicha entidad (Superintendencia de Economía Solidaria, 2016).

Las organizaciones de economía solidaria se definen como personas jurídicas organizadas para realizar actividades sin ánimo de lucro, en las cuales los trabajadores o usuarios, según el caso, son gestores y aportantes. Su objeto principal es la producción, distribución y consumo conjunto y eficiente de bienes y servicios, con el fin de satisfacer las necesidades de sus miembros y el desarrollo de obras al servicio de la comunidad (Ley 454, 1998). Las características de las organizaciones de economía solidaria, según el artículo 6 de dicha ley, son: a. Tener establecido un vínculo asociativo, fundado en los principios y fines contemplados en la presente ley.

b. Tener incluido en sus estatutos o reglas básicas de funcionamiento la ausencia de ánimo de lucro, movida por la solidaridad, el servicio social o comunitario.

c. Garantizar la igualdad de derechos y obligaciones de sus miembros sin consideración a sus aportes.

d. Establecer en sus estatutos un monto mínimo de aportes sociales no reducibles, debidamente pagados durante su existencia.

e. Integrarse social y económicamente, sin perjuicio de sus vínculos con otras entidades sin ánimo de lucro que tengan por fin promover el desarrollo integral del ser humano.

f. Establecer la irrepartibilidad de las reservas sociales y, en caso de liquidación, la del remanente patrimonial.

g. Destinar sus excedentes a la prestación de servicios de carácter social, al crecimiento de sus reservas y fondos, y a reintegrar a sus asociados parte de los mismos en proporción al uso de los servicios o a la participación en el trabajo de la empresa, sin perjuicio de amortizar los aportes y conservarlos en su valor real.

En Colombia estas organizaciones son apoyadas por el Departamento Administrativo Nacional de la Economía Solidaria (Dansocial) y el Consejo Nacional de la Economía Solidaria, quienes formulan, desarrollan y coordinan en el ámbito nacional políticas públicas, estrategias, programas y proyectos para el fomento y fortalecimiento de las organizaciones de economía solidaria.

Este tipo de organizaciones funcionan bajo los siguientes principios, los cuales están contenidos en el artículo 4 de la Ley 454 de 1998:

a. El ser bueno, su trabajo y mecanismos de cooperación sobre los medios de producción.

b. Espíritu de solidaridad, cooperación, participación y ayuda mutua.

c. Administración democrática, participativa, autogestionaria y emprendedora.

d. Adhesión voluntaria, responsable y abierta.

e. Propiedad asociativa y solidaria sobre los medios de producción.

f. Participación económica de los asociados, en justicia y equidad.

g. Formación e información para sus miembros, de manera permanente, oportuna y progresiva. 
h. Autonomía, autodeterminación y autogobierno.

i. Servicio a la comunidad.

j. Integración con otras organizaciones del mismo sector.

k. Promoción de la cultura ecológica.

A su vez, en el artículo 5 de la Ley 454 de 1998, se han establecido como fines de la economía solidaria:

a. Promover el desarrollo integral del ser humano.

b. Generar prácticas que consoliden una corriente vivencial de pensamiento solidario, crítico, creativo y emprendedor como medio para alcanzar el desarrollo y la paz de los pueblos.

c. Contribuir al ejercicio y perfeccionamiento de la democracia participativa.

d. Participar en el diseño y ejecución de planes, programas y proyectos de desarrollo económico y social.

e. Garantizar a sus miembros la participación y el acceso a la formación, el trabajo, la propiedad, la información, la gestión y distribución equitativa de beneficios sin discriminación alguna.

Dentro de las organizaciones que tienen el carácter de solidarias se enumeran en el artículo 6, parágrafo 2 de la Ley 454 de 1998:

Cooperativas, los organismos de segundo y tercer grado que agrupen cooperativas u otras formas asociativas y solidarias de propiedad, las instituciones auxiliares de la Economía Solidaria, las empresas comunitarias, las empresas solidarias de salud, las precooperativas, los fondos de empleados, las asociaciones mutualistas, las empresas de servicios en las formas de administraciones públicas cooperativas, las empresas asociativas de trabajo y todas aquellas formas asociativas que cumplan con las características mencionadas.

De este tipo de organizaciones, la cooperativa es la forma ideal de organización para los pequeños y medianos productores de yuca en Yopal, teniendo en cuenta que bajo esta figura es posible ejercer la actividad comercial y, a la vez, generar beneficios para los asociados y la comunidad a la que pertenecen.

Las organizaciones de economía solidaria en Colombia poseen tratamiento fiscal especial, debido a que pertenecen al régimen tributario especial, el cual cuenta con una serie de beneficios tributarios. Entre estos beneficios se encuentra una tarifa especial para el impuesto de renta y complementarios y la posibilidad de tener la exención de este impuesto. Además, algunas organizaciones de economía solidaria no están sujetas a impuesto al patrimonio (Rivera-Murcia, 2007).

El artículo 147 de la Ley 79 de 1988 establece que "los organismos cooperativos tendrán prelación obligatoria y tratamiento especial en la adjudicación de contratos con el Estado, siempre que cumpla los requisitos legales y se encuentren en iguales o mejores condiciones frente a los dos proponentes" (Ley 79, 1988). De acuerdo con lo anterior, se evidencia el beneficio de prelación obligatoria de las organizaciones de economía solidaria en la adjudicación de contratos con el Estado.

\section{Las formas asociativas de economía solidaria en la dinamización de la producción y comercialización de la yuca}

Los primeros antecedentes de asociatividad de los productores de yuca en Casanare "aparecen en el año 2001 a través de una iniciativa de transformación y comercialización conjunta de los productores de la región en bienes para la industria de alimentos concentrados, harina de yuca y otros productos que darían grandes rendimientos" (Botero-Soto, Delvasto-Rojas y Castro González, 2013, p. 23). Sin embargo, este proyecto no produjo los resultados pronosticados y generó desilusión a los pequeños productores de este, tanto así que reemplazaron el cultivo de yuca por otros productos.

Luego, en el 2005, se inauguró una planta procesadora de yuca en Aguazul Casanare, con una alta inversión que requería la producción mínima de 100 toneladas por día, pero esta iniciativa también fracasó porque no se cumplió con la producción mínima requerida debido a que eran muy pocos los productores de yuca que apoyaron esta propuesta (Botero-Soto, Delvasto-Rojas y Castro González, 2013). Por consiguiente, los pequeños y medianos productores no se han organizado en ninguna forma u organización de economía solidaria conocida que haya perdurado por un periodo prolongado.

Los pequeños y medianos productores de yuca, en su mayoría, presentan deficiencias en el manejo de la mano de obra utilizada para la producción, dadas por la informalidad en la contratación de la misma, lo cual hace que los trabajadores, al no contar con un contrato formal en algunas ocasiones no cumplen 
el horario establecido y dejan los trabajos abandonados en cualquier momento (Gil y Mendoza, comunicación personal, 18 de agosto del 2014).

De acuerdo con lo expuesto en el apartado anterior, y teniendo en cuenta el análisis de la cadena productiva, las formas asociativas se constituyen como mecanismos viables que permiten dar solución a problemas como el mencionado, ya que, en la medida que todos son solidarios con las obligaciones, existen incentivos para cumplir con las responsabilidades que cada uno adquiere en todo el proceso productivo. En ese sentido, al organizarse en cooperativas, es posible fortalecer las actividades productivas del cultivo de la yuca mediante estrategias conjuntas que generen valor agregado y fortalecimiento del producto en el sector, con el objeto de obtener beneficios conjuntos y un desarrollo equitativo y justo de cada asociado.

Así mismo, a partir de los beneficios tributarios mencionados anteriormente, los pequeños y medianos productores de yuca de Yopal pueden beneficiarse de la conformación de una organización de economía solidaria, de manera que además puedan acceder a las políticas públicas estatales y crear estrategias, programas y proyectos que fomenten el crecimiento y fortalecimiento del negocio de la yuca en la localidad y de todos los pequeños y medianos productores de esta.

Otra de las alternativas es que, al conformar organizaciones solidarias, estos productores de yuca puedan formar parte de alguna forma asociativa, teniendo en cuenta el principio de integración con otras organizaciones del mismo sector. Es importante mencionar que cualquier productor puede adherirse a una asociación de economía solidaria ya existente de forma voluntaria, responsable y abierta, y por ningún motivo debe sentirse obligado o sometido a pertenecer alguna de estas.

De acuerdo con los fines de la economía solidaria, los pequeños y medianos productores de yuca mediante su experiencia en la producción, pueden generar conocimientos y establecer practicas técnicas, empíricas y participativas, para el conocimiento y desarrollo eficiente del cultivo de todos los miembros, con el fin de maximizar equitativamente los recursos y ejecutar programas y proyectos para el desarrollo económico y social de los campesinos productores de yuca de Yopal.

\section{Conclusiones}

Las organizaciones de economía solidaria se vienen consolidando como una alternativa que permite aunar esfuerzos con el fin de crecer de manera sostenida en un entorno cada vez más competitivo, al tiempo que permiten a sus asociados trabajar bajo esquemas de crecimiento social y económico.

En Casanare, ya existen diferentes asociaciones de pequeños y medianos productores de diferentes productos agrícolas que han obtenido buenos resultados, y la yuca es uno uno de los cultivos de mayor crecimiento en el territorio colombiano por su adaptabilidad a diferentes condiciones del clima y del suelo. Estos factores han permitido que la producción de yuca se haya incrementado en el Orinoco en los últimos años. Por consiguiente, la producción de yuca es una alternativa de desarrollo económico y sustento de muchas familias de la región, la cual está apoyada por diferentes entidades nacionales y gubernamentales.

Por lo anterior, el hecho de que los pequeños y medianos productores de yuca de Yopal se organicen bajo las premisas de economía solidaria, puede permitir el fortalecimiento de las actividades que se desarrollan en la cadena de valor del negocio de la yuca en Yopal y disfrutar de los beneficios, fuentes de financiación y ventajas tributarias que poseen este tipo de organizaciones.

En la medida en que la investigación realizada se fundamenta en el reconocimiento inicial de las posibilidades de organización de los pequeños y medianos productores de yuca en Yopal, y teniendo en cuenta el potencial de crecimiento que tienen la producción y comercialización de este cultivo en la región, se recomienda que las entidades educativas tanto privadas como públicas realicen investigaciones que generen estrategias de crecimiento y desarrollo integral y sostenible.

Finalmente, esta invitación cabe también para que las entidades del Estado se involucren en el proceso de desarrollo de las organizaciones de economía solidaria, implementando planes, proyectos e incentivos para los pequeños y medianos agricultores de Yopal que desarrollan estrategias sociales y económicas de crecimiento y desarrollo de sus productos. 


\section{Referencias}

Aguilera-Díaz, M. (2012, enero). La yuca en el caribe colombiano de cultivo ancestral a agroindustrial. Cartagena: Banco de la República. Recuperado de www.banrep. gov.co/sites/default/files/publicaciones/archivos/dtser_158.pdf

Alcaldía de Yopal-Casanare. (s.f.).Alcaldía de Yopal-Casanare. Recuperado el 12 de Julio de 2014, de Alcaldía de Yopal-Casanare.

Arimany, L. (2010, noviembre). Luis Arimany. Recuperado el Agosto de 2015, de http://www.luisarimany.com/ la-cadena-de-valor

Botero-Soto, C. P., Delvasto-Rojas, L. A. y Castro-González, A. M. (2013). Contexto y desempeño y participación asociativa de los pequeños y medianos productores de las cadenas productivas de la yuca, la piña y el café en la región del Casanare (trabajo de grado). Universidad de La Salle, Bogotá.

Cáceres-Gómez, L. S., Pardo-Enciso, C. E. y Torres-Cárdenas, A. M. (2012). La asociatividad en la dinámica productiva del municipio de El Yopal Casanare. Gestión \& Sociedad, 5(2), 37-50. Recuperado de http://revistas. lasalle.edu.co/index.php/gs/article/view/2209

Consorcio de Desarrollo y Paz del Magdalena Medio (CDPMM) y el Programa Nacional de Transferencia de Tecnología Agropecuaria (Pronatta). (2001). Guía para el manejo agroecológico de cultivos en el corregimiento de la Indi. Recuperado de http://www.agronet.gov.co/ www/docs_si2/2006718125459_Guia\%20manejo\%20 agroecologico\%20de\%20yuca.pdf

Cultivo de grandes proyecciones. (1998, marzo 7). El Tiempo. Recuperado de http://www.eltiempo.com/archivo/ documento/MAM-749861s

Departamento Nacional de Planeación (DNP). (2013). Definición legal y funcional de los esquemas asociativos de entidades territoriales en Colombia.
Departamento de Ingeniería Agrónoma y Contenidos. (2012). Recuperado de http://www.infoagro.com/hortalizas/yuca.htm

Economía solidaria, un sector en crecimiento. (2013, enero 11). La República. Recuperado de http://www. larepublica.co/economia/econom\%C3\%ADa-solidaria-un-sector-en-crecimiento_28940

Howeler, R. H. y Ballesteros, D. (1987, julio). El cultivo de la yuca en los Llanos orientales de Colombia. Recuperado de pdf.usaid.gov/pdf_docs/PNABG495.pdf

Ley 454 de 1998. Do: 43.357.

Ley 79 de 1988. Do: 38.648 .

Porter, M. (2002). Ventaja competitiva. México: Alay Ediciones.

Rivera-Murcia, A. (2007, junio). Régimen Tributario Especial Sector Cooperativo Colombiano 1995-2005. Recuperado de www.dian.gov.co/descargas/servicios/ OEE-Documentos/Cuadernos/Regimen_Tributario_ Cooperativo.pdf

Centro Latinoamericano para el Desarrollo Rural a la Misión para la Transformación del Campo (Rimisp). (2014). Recuperado de https://colaboracion.dnp.gov. co/CDT/Agriculturapecuarioforestal\%20y\%20pesca/ Desarrollo\%20Rural\%20\%20Integral.pdf

Rojas-López, J. (2008). La agenda territorial del desarrollo rural en América Latina. Observatorio de la Economía Latinoamericana, (96). Recuperado de http://www.eumed.net/cursecon/ecolat/la/

Secretaría Distrital de Desarrollo Económico. (2008, enero). Formas asociativas de economía solidaria. Una alternativa clara para la inclusión y el desarrollo económico de Bogotá. Recuperado de www.desarrolloeconomico. gov.co/documentos/category/93-produccionintelectual\%3Fdownload\%3D1868:formasasociativaseconsolidaria $+\& c d=1 \& h \mathrm{l}=$ es $\& c t=c l n k$

Superintendencia de Economía Solidaria. (2016, mayo). Supersolidaria. Recuperado de http://www.supersolidaria.gov.co/es/nuestra-entidad/objetivos-estrategicos 